Technological University Dublin

ARROW@TU Dublin

2009-01-01

\title{
Silver Doped Perfluoropolyether-Urethane Coatings: Antibacterial Activity and Surface Analysis
}

\author{
Niall Stobie \\ Technological University Dublin, niall.stobie@tudublin.ie \\ Brendan Duffy \\ Technological University Dublin, brendan.duffy@tudublin.ie \\ Steven Hinder \\ University of Surrey, S.Hinder@surrey.ac.uk
}

See next page for additional authors

Follow this and additional works at: https://arrow.tudublin.ie/cenresart

Part of the Bacteriology Commons, Inorganic Chemistry Commons, and the Polymer Chemistry Commons

\section{Recommended Citation}

Stobie, N. et al. (2009) : Silver Doped Perfluoropolyether-Urethane Coatings: Antibacterial Activity and Surface Analysis. Colloids and Surfaces B: Biointerfaces Vol 72,1 (2009) ,pp.62-67. DOI:10.1016/ j.colsurfb.2009.03.014

This Article is brought to you for free and open access by the Crest: Centre for Research in Engineering Surface Technology at ARROW@TU Dublin. It has been accepted for inclusion in Articles by an authorized administrator of ARROW@TU Dublin. For more information, please contact arrow.admin@tudublin.ie, aisling.coyne@tudublin.ie,gerard.connolly@tudublin.ie. Funder: Enterprise Ireland

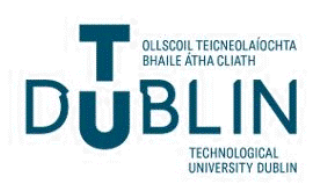




\section{Authors}

Niall Stobie, Brendan Duffy, Steven Hinder, Patrick McHale, and Declan McCormack

This article is available at ARROW@TU Dublin: https://arrow.tudublin.ie/cenresart/9 


\title{
Silver doped perfluoropolyether-urethane coatings: Antibacterial activity and surface analysis
}

\author{
Niall Stobie ${ }^{\mathrm{a}, \mathrm{b}}$, Brendan Duffy ${ }^{\mathrm{b}}$, Steven J. Hinder ${ }^{\mathrm{c}}$, Patrick McHale ${ }^{\mathrm{d}}$, Declan E. McCormack ${ }^{\mathrm{a}, *}$ \\ a School of Chemical and Pharmaceutical Sciences, Dublin Institute of Technology, Kevin Street, Dublin 8, Ireland \\ b Centre for Research in Engineering Surface Technology (CREST), FOCAS Institute, Dublin Institute of Technology, Dublin 8, Ireland \\ c The Surface Analysis Laboratory, Faculty of Engineering and Physical Sciences, University of Surrey, Guildford, Surrey GU2 7XH, UK \\ d School of Biological Sciences, Dublin Institute of Technology, Kevin Street, Dublin 8, Ireland
}

\section{A R T I C L E I N F O}

Article history:

Received 5 January 2009

Received in revised form 24 February 2009

Accepted 17 March 2009

Available online $\mathrm{xxx}$

\section{Keywords:}

Perfluoropolyether

Room temperature

Silver ion release

Antibacterial

\begin{abstract}
A B S T R A C T
The colonisation of clinical and industrial surfaces with pathogenic microorganisms has prompted increased research into the development of effective antibacterial and antifouling coatings. There is evidence that implanted biomedical surfaces coated with metallic silver can be inactivated by physiological fluids, thus reducing the bioactivity of the coating. In this work, we report the biofilm inhibition of Staphylococcus epidermidis using a room temperature processed silver doped perfluoropolyether-urethane coating. The release of silver ions from these fluoropolymers over a six-day period inhibited bacterial encrustation - as observed by scanning electron microscopy (SEM). X-ray photoelectron spectroscopy (XPS) analysis indicated differences in carbon, fluorine and sodium surface composition between silver doped and undoped fluoropolymers after exposure to nutrient rich media. These silver doped perfluoropolyether coatings also exhibited antibacterial activity against methicillin-resistant Staphylococcus aureus (MRSA), Escherichia coli, Pseudomonas aeruginosa and Acinetobacter baumannii; suggesting potential use in preventing transmission of pathogenic and opportunistic microbes on environmental surfaces in healthcare facilities. The broad-spectrum antibacterial activity of these silver release coatings may be exploited on biomaterials surfaces to combat the development of resistant Gram-negative Enterobacteriaceae that can occur during prophylactic treatment for urinary tract infections.
\end{abstract}

(c) 2009 Elsevier B.V. All rights reserved.

\section{Introduction}

Bacteria such as Staphylococcus aureus have shown adaptibility to changing environments in the healthcare setting, but also more recently in the wider community [1-3]. Opportunistic pathogens such as S. aureus and Pseudomonas aeruginosa, along with other bacteria, can develop resistance through an elaborate array of mechanisms. These include modification of the target protein or binding site, enzymatic destruction of antibacterial agents, active efflux of drugs from the bacterial cell or by acquisition of genetic material from other resistant strains [4,5]. The emergence of bacterial resistance often occurs shortly after the introduction of a new antibacterial agent. An increase in resistance can be observed by an elevated minimum inhibitory concentration (MIC) of the antibacterial agent [6]. This can be exemplified by the rapid emergence of Enterococcus faecium resistance to anti-VRE/MRSA antibiotics, such as linezolid [7].

\footnotetext{
* Corresponding author. Tel.: +3531 4024778; fax: +35314024989.

E-mail address: declan.mccormack@dit.ie (D.E. McCormack).
}

The reduction in the number of available antibacterial therapies for the treatment of multi-drug resistant pathogens, has resulted in a reversion to older antimicrobial agents, such as silver [8]. In medical terms, silver is the antimicrobial metal best known for its broad-spectrum activity against intractable infectious microorganisms, including antibiotic resistant strains [8]. The multiple modes of action of silver include binding with cell DNA, inhibiting enzymes that mediate respiration and reacting with sensitive thiol groups on bacterial proteins - thereby destroying the normal biological activity of the protein [9]. The antimicrobial properties of nanosilver loaded filter paper against Escherichia coli have been recently studied [10]. The use of medical device coatings as release or delivery vehicles for these biocidal silver ions has received significant attention recently. Silver ion release from sol-gel coatings has demonstrated antibacterial activity against $S$. aureus and E. coli [11-12]. Nanosilver coated fabric inhibited the growth of the Gramnegative bacterium E. coli [13]. Silver coated PTFE surfaces have shown antibacterial activity, but direct coating of silver onto a surface can be inactivated by biological anions with subsequent surface encrustation $[14,15]$. Previously reported studies have shown the benefit of silver impregnation in place of metallic silver deposition [16], although traditional techniques for the deposition or impregnation of silver employ high temperature processing, which limits 
substrate choice and increases costs [11,16]. In addition, one of the factors governing silver ion release from a coating matrix is the hydrophilicity of the coating [17]. Therefore, coatings with purely hydrophobic components will have limited water affinity and consequently a low silver release. This route may be ineffective, as coatings that release low levels of silver may select for resistance [18].

Polyether polyurethanes are low friction, biocompatible, elastomeric polymers that have been investigated as anti-fouling and biomedical coatings [19]. However, they are prone to biodegradation and environmental stress-cracking due to interactions with lysomal oxygen-free radicals and transition metal ions from implanted devices [20]. Polyether urethanes containing silver nanoparticles have shown improved biostability due to the free radical scavenging ability of the silver nanoparticles [21]. Modification of these polymers with fluorocarbons has been reported to improve biostability as fluorocarbons are stable against hydrolysis and oxidation [22].

In this work, we present the preparation, antibacterial activity and surface analysis of silver doped perfluoropolyether-urethane coatings. Silver ion release from these fluorinated dispersions exhibited significant antibacterial activity against MRSA, E. coli, $P$. aeruginosa and Acinetobacter baumannii. SEM was employed to examine the surfaces of the doped and undoped coatings after exposure to a biofilm-positive strain of $S$. epidermidis. XPS surface analysis provided information on the elemental and chemical composition of the coatings before and after exposure to different media. The surface composition of the silver doped fluoropolymers did not display significant changes in surface chemistry after six days bacterial exposure. In contrast, the blank fluoropolymers showed increased surface carbon and sodium levels, with a reduction in fluorinated content. The antibacterial capacity of the silver doped fluoropolymers was challenged by exchanging the nutrient rich medium every $24 \mathrm{~h}$. After six days bacterial exposure, the supernatant broth still contained enough bio-active silver ions to inhibit planktonic S. epidermidis. In summary, these room temperature processed coatings may be employed in reducing contamination and biofouling on short-term indwelling devices and environmental surfaces.

\section{Experimental}

Silver doped fluoropolymers were prepared by the addition of a silver nitrate salt to an anionic perfluoropolyether (PFPE) urethane polymer, Fluorolink ${ }^{\circledR}$ P56 ( $M_{\mathrm{w}} \approx 20,000$, Solvay) [23]. $55 \mathrm{mg}$ $(0.3 \mathrm{mmol})$ silver nitrate (Aldrich) was dissolved by sonication in $2.5 \mathrm{ml}(0.2 \mathrm{~mol})$ de-ionised water containing $2.5 \mathrm{~g}$ polyaziridine cross-linker CX-100 (Neoresins). This solution was slowly added to the anionic fluorinated dispersion ( $95 \mathrm{~g}$ ) under stirring. A silver nitrate free control was similarly prepared. The silver doped fluoropolymers were prepared in amber glassware to prevent photoreduction of the silver ions. The resulting silver doped and undoped polymers were applied to pre-cleaned tin coated steel and glass substrates using a $100 \mu \mathrm{m}$ film applicator and cured at room temperature for $4 \mathrm{~h}$, resulting in nominal film thickness of approximately $30 \mu \mathrm{m}$. The prepared coatings showed no tendency towards delamination or cracking before or after testing.

\subsection{Instrumentation}

The release of silver from the coatings was determined by GFAAS using a Varian 110 Spectrometer equipped with a silver hollow cathode lamp. Microanalysis of the coatings was assessed using a Jeol 8600 scanning electron microscope (SEM). The samples were mounted on stubs and gold coated for SEM imaging at $10 \mathrm{KeV}$.
XPS analysis employed an ESCALAB Mk II spectrometer equipped with a twin anode X-ray source was used to analyse the surface composition $(\approx 10 \mathrm{~nm}$ ) of the fluoropolymers and silver doped fluoropolymers. The instrument was equipped with a twin anode X-ray source $(\mathrm{AlK} \alpha / \operatorname{MgK} \alpha)$ and an Alpha 110 analyser. In this work the twin anode AlK $\alpha$ X-ray source $(h \nu=1486.6 \mathrm{eV})$ was used at $300 \mathrm{~W}$ $(15 \mathrm{kV} \times 20 \mathrm{~mA})$. Quantitative surface chemical analyses were calculated from the high resolution, core level spectra following the removal of a non-linear (Shirley) background. All spectrum binding energies were referenced to the hydrocarbon $C 1$ s peak at $285 \mathrm{eV}$ to correct for electrostatic charging effects during acquisition. Sample mounting for XPS analysis was achieved by fixing a specimen to a VG sample stub using double sided adhesive tape.

\subsection{Silver release}

Silver doped perfluoropolyether coated glass substrates $\left(25 \mathrm{~cm}^{2}\right)$ were immersed in $50 \mathrm{ml}$ of physiological buffered saline (PBS) at $37^{\circ} \mathrm{C}$ initially for $1 \mathrm{~h}$, followed by six successive $24 \mathrm{~h}$ immersion periods. Fresh media was used for each immersion period. Silver values are expressed in $\mathrm{ppb}(\mu \mathrm{g} / \mathrm{L})$. The fluids were collected after each immersion period and analysed using GF-AAS.

\subsection{Antibacterial activity}

The antibacterial activity of the silver doped and undoped fluoropolymers, against a selection of Gram-positive and Gramnegative strains, was determined using a modified version of the Japanese standard (JIS Z 2801). These bacterial strains include MRSA (clinical isolate) S. aureus (ATCC 25922), P. aeruginosa (ATCC 27853), A. baumannii (clinical isolate) and a biofilm-positive strain of S. epidermidis (CSF 41498). Stock cultures of the bacteria were grown on plate count agar (PCA-3 w/v\% tryptone, $1 \mathrm{w} / \mathrm{v} \%$ glucose, $2.5 \mathrm{w} / \mathrm{v} \%$ yeast, $9 \mathrm{w} / \mathrm{v} \%$ agar, Oxoid). The organisms were grown overnight in nutrient rich broth to give a concentration of approximately $10^{8} \mathrm{CFU} / \mathrm{ml}$. These were diluted one in a hundred with maximum recovery diluent (MRD - $1 \mathrm{w} / \mathrm{v} \%$ peptone, $8.5 \mathrm{w} / \mathrm{v} \% \mathrm{NaCl}$, Oxoid) to give a working culture of approximately $10^{6} \mathrm{CFU} / \mathrm{ml}$. Doped and undoped coatings $\left(25 \mathrm{~cm}^{2}\right)$ were inoculated with $400 \mu$ l of the working bacterial cultures and incubated at $37^{\circ} \mathrm{C}$ overnight. The coatings were then agitated with $\operatorname{MRD}(20 \mathrm{ml})$ in sterile stomacher bags. To determine the number of colonies, the MRD was serially diluted tenfold and the resulting dilutions plated $(100 \mu \mathrm{l})$ onto plate count agar (PCA) for overnight incubation at $37^{\circ} \mathrm{C}$.

\subsection{Biofilm growth}

Silver doped and undoped perfluorinated polymers were applied to pre-cleaned tin panels and allowed to cure for $4 \mathrm{~h}$. Plastic wells were glued to the surface of the coatings using an epoxy fixative (Epofix) and left to cure for $24 \mathrm{~h}$ (Fig. 1). $5 \mathrm{ml}$ of tryptic soy broth (TSB - tryptone $17 \mathrm{~g} / \mathrm{L}$, soy peptone $3 \mathrm{~g} / \mathrm{L}, \mathrm{NaCl} 5 \mathrm{~g} / \mathrm{L}$, dipotassium hydrogen phosphate $2.5 \mathrm{~g} / \mathrm{L}$, dextrose $2.5 \mathrm{~g} / \mathrm{L}$ ), supplemented with $0.25 \%$ glucose was added to the wells. $50 \mu$ l of approximately $10^{8} \mathrm{CFU} / \mathrm{ml}$ S. epidermidis (CSF 41498) culture was added to the glucose modified TSB broth and the resulting bacterial broth poured into the wells and incubated for $24 \mathrm{~h}$ at $37^{\circ} \mathrm{C}$. The TSB medium was removed and replaced with fresh glucose modified TSB every $24 \mathrm{~h}$ and subsequently incubated at $37^{\circ} \mathrm{C}$. This process was repeated for six days. The daily exchange of nutrient rich media is useful in challenging the antibacterial capacity of the coating over the six days. Finally, the medium was decanted off and the coatings washed twice with sterile water. SEM was used to examine the surface of the coatings for the presence of any extraneous matter. Detailed surface elemental and chemical composition of the fluoropolymer coatings was obtained using XPS. 




Fig. 1. Non-cumulative release of silver into fresh PBS media from Ag doped fluoropolymer (determined by GF-AAS).

\section{Results and discussion}

\subsection{Silver release}

The incorporation of silver salts into hydrophobic sol-gel coatings has been reported to initially release high levels of silver ions, followed by a more gradual and sustained release profile [12]. In this work, the release of silver ions into PBS solution at $37^{\circ} \mathrm{C}$ over six days is depicted in Fig. 1. Initially after $1 \mathrm{~h}$, approximately $300 \mathrm{ppb}$ was released into the PBS solution, followed by a more sustained release profile for six days. As the first $6 \mathrm{~h}$ after device implantation is reported as being critical in reducing initial bacterial adhesion [24], this initial high release of a broad-spectrum antibacterial agent is favourable. XPS was employed to examine the surface composition of the coatings before and after exposure to external media. XPS is a useful analytical tool in bioengineering for determining the atomic composition of specific functional groups in the first $10 \mathrm{~nm}$ of a surface coating. This technique was previously employed to determine the surface composition of antibacterial furanones [25]. XPS measurements of the silver doped coatings before and after immersion in PBS indicated the appearance of a urethane related peak at the coating surface following immersion (Fig. 2). This specific peak at $532 \mathrm{eV}$ is associated with the carbonyl oxygen of $(-\mathrm{NH}-(\mathrm{C}=\mathrm{O})-\mathrm{O}-)$ [23]. This migration of polar species has been previously reported with polyethylene glycol (PEG) modified PFPE coatings [26]. Such polymers demonstrated surface adaptable properties when immersed in a polar medium such as water. As PFPE molecules migrate to the air interface, the PEG molecules also migrate. As a result, when the PEG modified PFPE polymer is immersed in water the more polar PEG molecules stratify to the air interface [26]. In this work, we observed a similar phenomenon

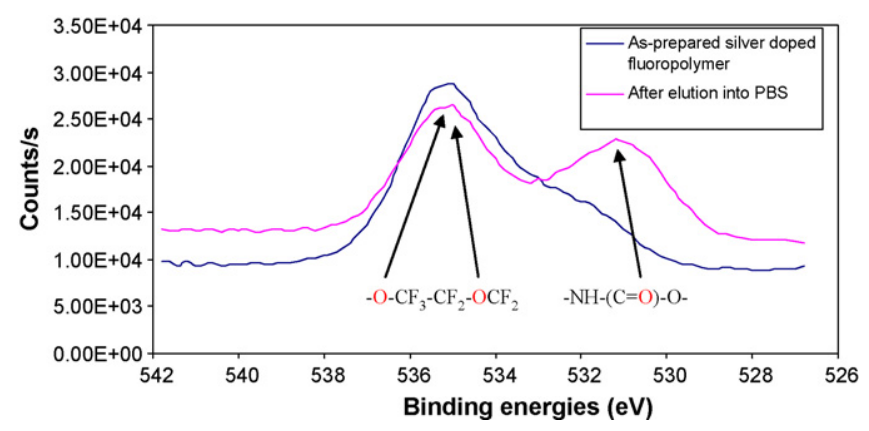

Fig. 2. O 1s XPS surface spectra of silver doped fluoropolymer before and after immersion in PBS.

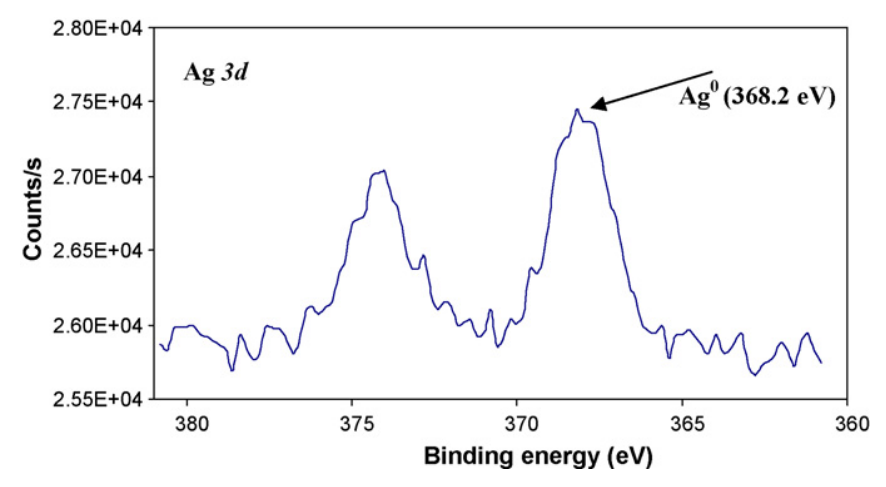

Fig. 3. Ag 3d XPS surface spectra of as-prepared Ag doped fluoropolymer coating.

with the stratification of the urethane species to the air-interface after immersion in aqueous media. The presence of silver in the as-prepared surface coating can be confirmed by the presence of the peak at $368.2 \mathrm{eV}$ [12]. The presence of silver in the coating was confirmed by XPS analysis with a percentage atomic concentration of $0.04 \%$ (Fig. 3). No surface silver was observed on the coating after exposure to PBS. The daily exchange of anionic species such as chlorides and phosphates in the PBS would have depleted the available surface silver, by the possible formation of $\mathrm{AgCl}$ and $\mathrm{Ag}_{3} \mathrm{PO}_{4}$ precipitates on the coating surface [27]. No visible precipitates were observed in the PBS solutions after silver release. No surface phosphorus was observed by XPS and the percentage atomic sodium and chlorine was $3.2 \%$ and $0.91 \%$, respectively.

\subsection{Antibacterial activity}

The release of silver ions from the perfluorinated coatings had a significant antibacterial effect against MRSA (clinical isolate) $S$. aureus (ATCC 25922), P. aeruginosa (ATCC 27853), A. baumanii (clinical isolate) and a biofilm-positive strain of $S$. epidermidis (CSF 41498) (Fig. 4). Overnight incubation of the inoculated coatings resulted in approximately $99 \%\left(>10^{3} \mathrm{CFU} / \mathrm{ml}\right)$, reduction in bacterial colonies compared to undoped samples after $24 \mathrm{~h}$. The broadspectrum activity suggests the use of these hygienic coatings in preventing environmental contamination on hand rails, bedside rails, door handles and other transmissible surfaces in healthcare environments. This is important as patients who are infected with healthcare and community associated microbes may shed bacteria onto fomites such as those found in hospitals, nursing homes, childcare facilities, prisons and public transport [28]. In addition, as silver ion release is governed by water diffusion through the coating [17], the use of water as a cleaning agent, in-place of standard antiseptics and detergents, may be sufficient to generate a bio-active surface.

\subsection{Biofilm growth}

Biofilms are complex assemblages of microorganisms that bind to host surfaces that can cause device failure and pathogenesis. Sessile bacterial cells provide diffusion barriers to prophylactic treatment by binding with antibiotics. Furthermore, the close proximity of bacterial cells facilitates the spreading of antibiotic resistant plasmids (extra-chromosomal material) thus altering antimicrobial susceptibility [29]. The bacterial cells that reside near the substratum are in anoxic regions and are thus slow growing, leading to an intrinsic tolerance to antibiotic dosage - relative to the aerobic cells in the peripheral layers of the biofilm [30]. S. epidermidis is the most common bacterium isolated from medical devices such as vascular catheters, prosthetic implants and intrauterine devices [27]. Several strategies have been investigated in preventing biofilm growth 


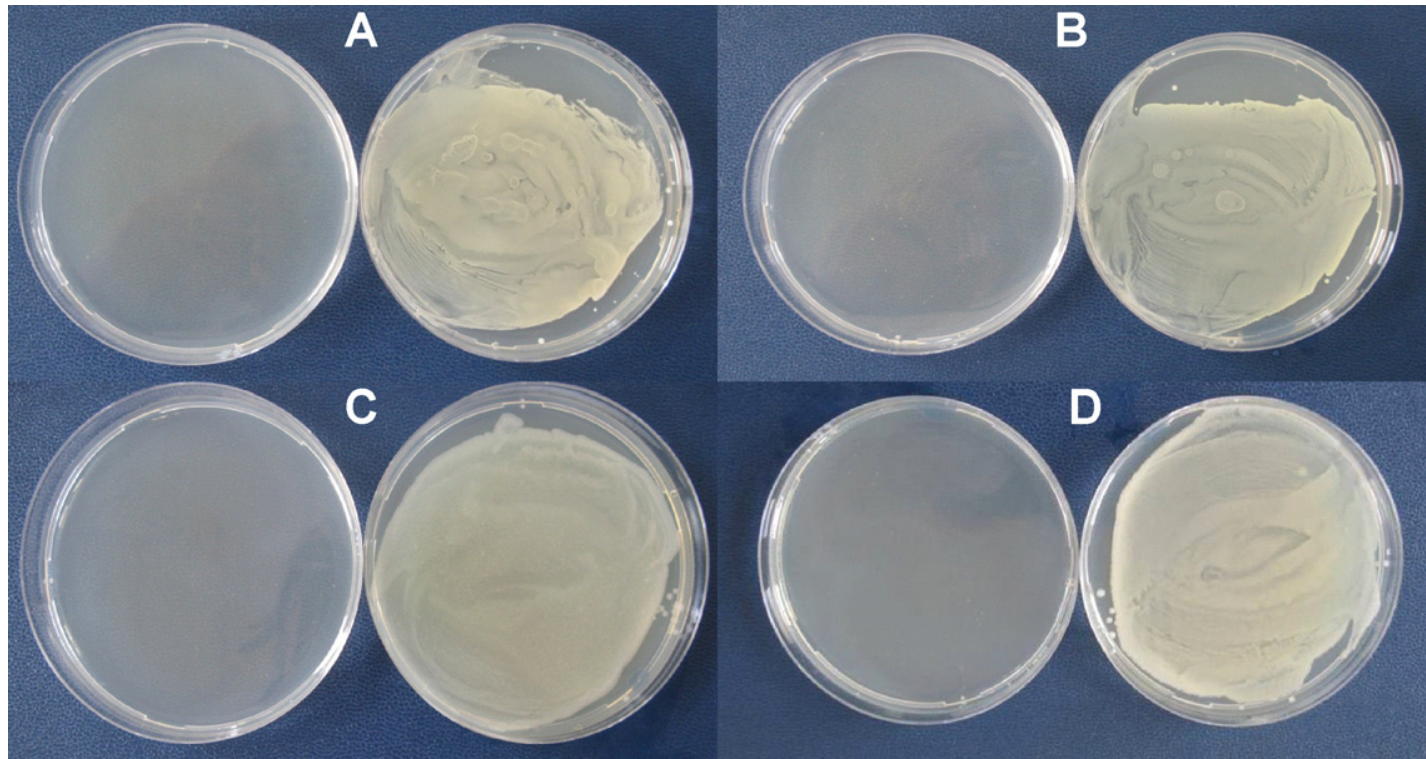

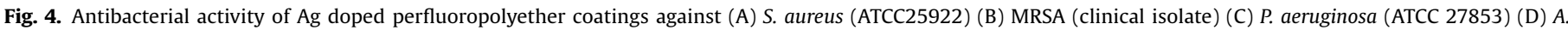
baumanii (clinicalisolate). Left plate: Silver doped fluoropolymer. Right plate: undoped fluoropolymer. (JIS Z 2801).

on indwelling biomaterials [31]. One of these techniques involves the functionalisation of the indwelling surfaces; to include active antibacterial agents on the biomaterial surface. Antibiotics function by targeting specific biomolecular pathways and as a result have a propensity for the development of resistance to prophylactic treatment. This emergence of antibiotic resistance has prompted a resurgence in the use of biocidal metals, such as silver.

Due to the broad-spectrum activity at relatively low concentrations, silver technology has been employed in various applications such as medical devices [32], household appliances and water treatment [33]. Low concentrations ( $<35 \mathrm{ppb})$ are reported to be bactericidal [34], whilst higher concentrations between $1 \mathrm{ppm}$ and $10 \mathrm{ppm}$ may cause damage to human cells, ranging from low localised toxicity to conditions like argyria in higher doses ( $>4-6 \mathrm{~g}$ in the body) [35]. Histopathologic examination of silver coated megaprostheses in humans showed no signs of local or systemic side-effects at concentrations up to $1627 \mathrm{ppb}$ [36].

Silver impregnated catheters have been reported to demonstrate superior inhibition of bacterial colonisation than antibiotic impregnated catheters [37,38]. The effect of silver ions on biofilms has been recently reported $[39,40]$. Addition of silver ions at a concentration of $50 \mathrm{ppb}$ to an existing biofilm had a diffusion limiting effect, as sessile bacteria can sequester the silver ions into the anionic polysaccharide components, reducing penetration and thus rendering them inactive [40]. Therefore, it is crucial to inhibit biofilm formation by reducing this initial surface bacterial adhesion [24]. In biological systems, the interaction between $S$. epidermidis bacterial cells and surfaces are mediated by hydrophobic forces [41]. In particular, the presence of hydrophobic chains in the fluoropolymer may facilitate the microbial hydrophobic attraction of Staphylococcal bacterial cells to the biomaterial surface. It has been reported that a large quantity of microbial pathogens are dependent on hydrophobic interactions for successful colonisation of host substrates [42].

In this study, the effect of silver ion release on surface encrustation can be observed in the SEM images in Fig. 5. The blank perfluoropolyether-urethane coating is covered in adherent bacterial deposits (Fig. 5a). Silver ion release from the doped fluoropolymer reduced the colonisation of extraneous matter on the coating surface (Fig. 5b). Additional XPS elemental and chemical composition of the coatings indicated differences in surface chemical composition ( $10 \mathrm{~nm}$ ) between the fluoropolymer and the silver doped fluoropolymer after six days exposure to S. epidermidis bacterial broth. The difference in percentage atomic carbon (38.9\% to 50.8\%) (Fig. 6) and consequent reduction in atomic fluorine (35.2\% to $17.5 \%$ ) (Fig. 7 ) between silver doped and undoped

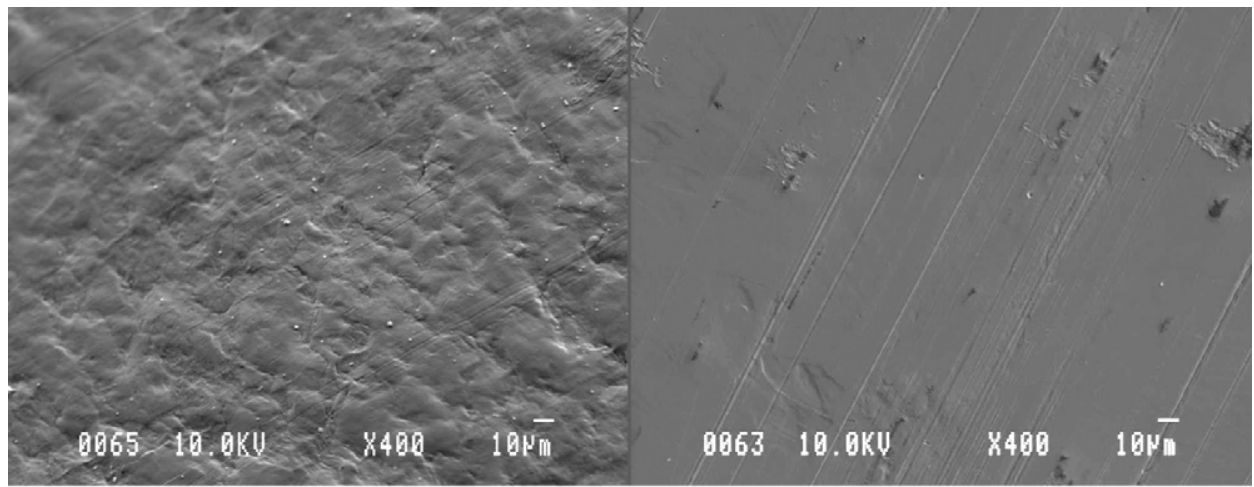

(a)

(b)

Fig. 5. SEM of fluoropolymer coating (a) and silver doped fluoropolymer (b) after six days S. epidermidis, bacterial broth incubation.

Please cite this article in press as: N. Stobie, et al., Silver doped perfluoropolyether-urethane coatings: Antibacterial activity and surface analysis, Colloids Surf. B: Biointerfaces (2009), doi:10.1016/j.colsurfb.2009.03.014 


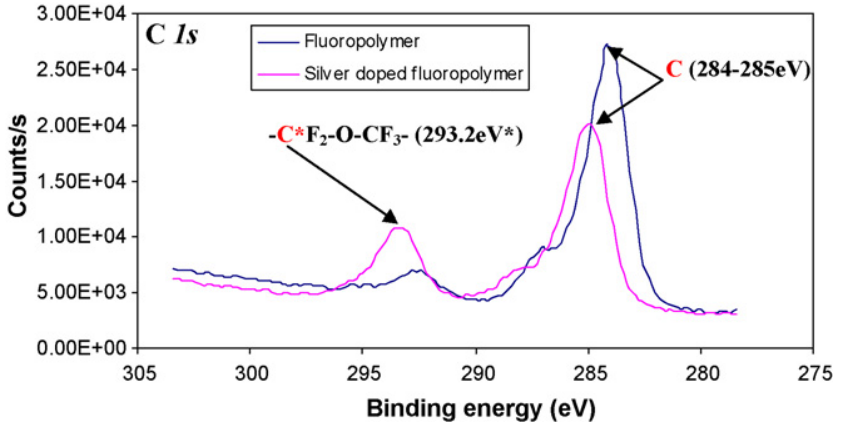

Fig. 6. C 1s XPS surface spectra of fluoropolymer and silver doped fluoropolymer after six days $S$. epidermidis bacterial broth incubation.

perfluorinated coating may be attributed to bacterial accumulation on the fluoropolymer surface. The peak at $293.2 \mathrm{eV}$ corresponding to $-\mathrm{C}^{*} \mathrm{~F}_{2}-\mathrm{O}-\mathrm{CF}_{3}$ is present in the as-prepared fluoropolymer but disappears after bacterial exposure (Fig. 6). Incorporation of a silver salt in the fluoropolymer maintained this functional group at the air-interface, by inhibiting planktonic bacterial adhesion and subsequently reducing surface encrustation. Furthermore, there was a reduction in percentage atomic sodium (Fig. 8), potassium, chlorine and nitrogen on the surface of the silver doped fluoropolymer coating (Table 1). The percentage of atomic silver present in the as-prepared silver doped fluoropolymer was $0.04 \%$ but no surface silver was detected by XPS post bacterial incubation, analogous to PBS elution. In addition to the broad-spectrum antimicrobial activity against planktonic strains, silver ion elution reduced bacterial colonisation on the coating surface. Furthermore, as biofilm fragments may detach and the seed into surrounding fluids [43], it is important to inhibit any free floating or planktonic bacteria. After six days bacterial exposure, the supernatant broth still contained enough bio-active silver ions to inhibit planktonic $S$. epidermidis



Fig. 7. F 1s XPS surface spectra of fluoropolymer and silver doped fluoropolymer after six days $S$. epidermidis bacterial broth incubation.

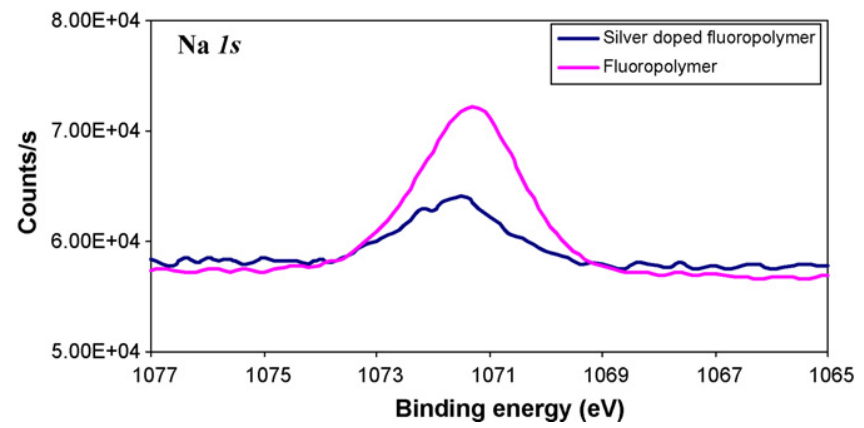

Fig. 8. Na 1s XPS surface spectra of fluoropolymer and silver doped fluoropolymer after six days $S$. epidermidis bacterial broth incubation.
Table 1

Summary of XPS data, before and after exposure to S. epidermidis broth for six days.

\begin{tabular}{llllll}
\hline Coating type & \multicolumn{2}{c}{ \% XPS elemental composition } & & \\
& $\mathrm{Ag}$ & $\mathrm{C}$ & $\mathrm{F}$ & $\mathrm{O}$ & $\mathrm{Na}$ \\
\hline $\begin{array}{l}\text { Initial } \\
\quad \text { fluoropolymer }\end{array}$ & 0 & 29.2 & 52 & 17 & 0 \\
$\begin{array}{l}\text { Initial Ag } \\
\text { fluoropolymer }\end{array}$ & 0.04 & 35.5 & 44.8 & 17 & 0 \\
$\begin{array}{c}\text { Fluoropolymer } \\
\quad \text { after six days } \\
\text { bacterial } \\
\text { exposure }\end{array}$ & 0 & 50.8 & 17.5 & 19 & 4.7 \\
$\begin{array}{c}\text { Ag fluoropolymer } \\
\text { after six days } \\
\text { bacterial } \\
\text { exposure }\end{array}$ & 0 & 38.9 & 35.2 & 18 & 2.6 \\
\hline
\end{tabular}

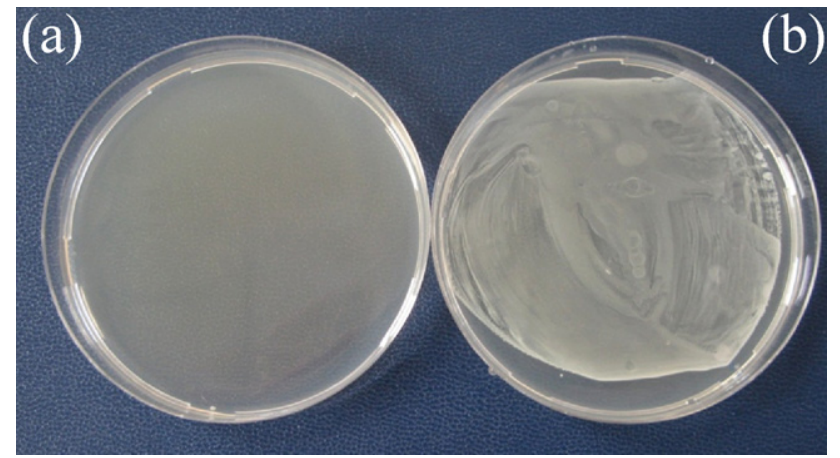

Fig. 9. Antibacterial activity of biofilm extraction media against planktonic S. epidermidis (CSF 41498) after exposure to silver doped fluoropolymer (a) fluoropolymer (b)

(Fig. 9). Furthermore, these silver ion releasing coatings may be beneficial in reducing mineral precipitation and the associated biofilm formation, by reducing the number of viable cells from the urease producing Proteus mirabilis.

\section{Conclusion}

The tremendous resistance of biofilms to conventional prophylactic agents has prompted a great deal of research on biomaterial surfaces and coatings that can reduce bacterial colonisation with subsequent device removal. In this paper, we propose the use of a room temperature processed silver release perfluoropolyether-urethane coating, in reducing the surface colonisation on biomedical and environmental surfaces. XPS analysis provided useful information on the surface composition of the coatings before and after exposure to PBS and S. epidermidis bacterial broth. The silver free fluoropolymer exhibited higher carbon and sodium content, with a consequent reduction in fluorine content, in comparison to the silver containing fluoropolymer. The release of silver ions from these fluorinated coatings demonstrated antibacterial activity against MRSA, $P$. aeruginosa, A. baumannii and S. epidermidis. There was approximately $99 \%$ reduction in the number of bacterial colonies in comparison to the control fluoropolymer. The antibacterial capacity of these coatings was challenged by the daily exchange of nutrient rich medium. These antibacterial coatings can also be used to deliver alternative metal ions ( $\mathrm{Zn}$, $\mathrm{Cu})$ to inhibit fungal/algal growth and contamination on environmental surfaces. As silver is a broad-spectrum antimicrobial, these short-term indwelling coatings have the potential to combat resistant Gram-negative Enterobacteriaceae that can occur after fluoroquinolone, cephalosporin or glycopeptide administration for urinary tract infections. The low temperature processing requirements of these silver release coatings makes them suitable for the judicious protection of various surfaces against bacterial infection. 


\section{References}

[1] A. Pantosti, A. Sanchini, M. Monaco, Future Microbiol. 2 (2007) 323.

[2] F.C. Tenover, Am. J. Infect. Control 34 (2006) S3.

[3] S.F. Bloomfield, B. Cookson, F. Falkiner, C. Griffith, V. Cleary, Am. J. Infect. Control 35 (2007) 86

[4] P.F. McDermott, R.D. Walker, D.G. White, Int. J. Toxicol. 22 (2003) 135

[5] L.B. Rice, Am. J. Infect. Control 34 (2007) S11.

[6] L.J.V. Piddock, Nat. Rev. Microbiol. 4 (2006) 629.

[7] J. Seedat, G. Zick, I. Klare, C. Konstabel, N. Weiler, H. Sahly, Antimicrob. Agents Chemother. 50 (2006) 4217.

[8] J.R. Ellis, Am. J. Infect. Control 35 (2007) E26.

[9] A. Melaiye, W.J. Youngs, Expert Opin. Ther. Pat. 15 (2005) 125.

[10] R. Tankhiwale, S.K. Bajpai, Colloids Surf. B: Biointerfaces 2008, http://dx.doi.org/10.1016/j.colsurfb.2008.11.004.

[11] H.J. Jeon, S.C. Yi, S.G. Oh, Biomaterials 24 (2003) 4921

[12] N. Stobie, B. Duffy, D.E. McCormack, J. Colreavy, M. Hidalgo, P. McHale, S.J. Hinder, Biomaterials 29 (2008) 963.

[13] H.Y. Lee, H.K. Park, Y.M. Lee, K. Swan, S.B. Park, Chem. Commun. 28 (2007) 2959.

[14] O. Zhao, C. Wang, Y. Liu, S. Wang, Int. J. Adhes. Adhes. 27 (2007) 85.

[15] R.F. Brady, Prog. Org. Coat. 35 (1999) 31.

[16] F. Furno, K.S. Morley, B. Wong, B.L. Sharp, P.L. Arnold, S.M. Howdle, R. Bayston, P.D. Brown, P.D. Winship, H.J. Reid, J. Antimicrob. Chemother. 54 (2004) 1019.

[17] R. Kumar, H. Münstedt, Polym. Int. 24 (2005) 1180.

[18] D.W. Brett, Ostomy Wound Manage. 52 (2006) 34

[19] M. Wouters, Jv. Zanten, T. Vereijken, D. Bakker, J. Klijnstra, Surf. Coat. Int. Pt B-C 89 (2006) 23.

[20] R. Ward, J. Anderson, R. McVenes, K. Stokes, J. Biomed. Mater. Res. A 79A (2006) 836.

[21] C.W. Chou, S.H. Hsu, P.H. Wang, J. Biomed. Mater. Res. A 84 (2008) 785.

[22] R. Ward, J. Anderson, R. McVenes, K. Stokes, J. Biomed. Mater. Res. A 80A (2007) 34.

[23] R. Canteri, G. Speranza, M. Anderle, S. Turri, S. Radice, Surf. Interface Anal. 35 (2003) 318
[24] E.M. Hetrick, M.H. Schoenfisch, Chem. Soc. Rev. 35 (2006) 780.

[25] S.A. Al-Bataineh, L.G. Britcher, H.J. Grisser, Surf. Sci. 600 (2006) 952.

[26] A. Vaidya, M.K. Chaudhury, J. Colloid Interface Sci. 49 (2002) 235.

[27] D. Roe, B. Karandikar, N. Bonn-Savage, B. Gibbins, J.B. Roullet, J. Antimicrob. Chemother. 61 (2008) 869

[28] B.C. Eckstein, D.A. Adams, E.C. Eckstein, A. Rao, A.K. Seithi, G.K. Yadavlli, C.J Donskey, BMC Infect. Dis. 7 (2007) 61.

[29] A.G.B. Lansdown, A. Williams, J. Wound Care 16 (2007) 15.

[30] J.J. Harrison, H. Ceri, R.J. Turner, Nat. Rev. Microbiol. 5 (2007) 928.

[31] J.B. Kaplan, Expert Opin. 15 (2005) 955.

[32] Y. Izci, H. Secer, C. Akay, E. Gonul. Neurol. Res. (2008) doi:10.1179/174313209X380973.

[33] Q. Li, S. Mahendra, D.Y. Lyon, L. Brunet, M.V. Liga, D. Li, P.J.J. Alvarez, Water Res. 42 (2008) 4591.

[34] A. Ewald, S.K. Glückermann, R. Thull, U. Gbureck, Biomed. Eng. Online 52 (2006) 22.

[35] G. Gosheger, J. Hardes, H. Ahrens, A. Streitburger, H. Buerger, M. Erren, A. Gunsel, F.H. Kemper, W. Winkelmann, C. von Eiff, Biomaterials 25 (2004) 5547.

[36] J. Hardes, H. Ahrens, C. Gebert, A. Streitbuerger, H. Buerger, M. Erren, A. Gunsel, C. Wedemeyer, G. Saxler, W. Winkelmann, G. Gosheger, Biomaterials 28 (2007) 2869.

[37] H.I. Secer, C. Kural, M. Kaplan, A. Kilic, B. Duz, E. Gonul, Y. Izci, Pediatr. Neurosurg. 44 (2008) 444.

[38] K. Galiano, C. Pleifer, K. Engelhardt, G. Brossner, P. Lackner, C. Huck, C. Lass-Florl, A. Obwegeser, Neurol. Res. 30 (2008) 285

[39] K.C. Chaw, M. Manimaran, F.E.H. Tay, Antimicrob. Agents Chemother. 49 (2005) 4853.

[40] N.S. Rodriguez, K.R. Bright, D.C. Slack, D.R. Uhlmann, C.P. Gerba, Appl. Environ. Microbiol. 74 (2008) 1639.

[41] N. Cerca, G.B. Pier, M. Vilanova, R. Olivereira, J. Azeredo, Res. Microbiol. 156 (2005) 506.

[42] R.J. Doyle, Microbes Infect. 2 (2000) 391.

[43] A.L. Casey, L.A. Mermel, P. Nightingale, T.S.J. Elliott, Lancet Infect. Dis. 8 (2008) 763. 